\title{
Parâmetros genéticos de frutos, sementes e plântulas de Jatropha ribifolia (Pohl) Baill. (Euphorbiaceae)
}

\begin{abstract}
LYRA, D.H. ${ }^{1 *}$; ALMEIDA, L.A.H. ${ }^{2}$; BRASILEIRO, B.P. ${ }^{3}$; SANT'ANA, M.R. ${ }^{4}$; AMARAL, C.L.F. ${ }^{4}$ ${ }^{1}$ Departamento de Biologia, Universidade Federal de Lavras (UFLA), Caixa Postal 3037, CEP: 37200-000, LavrasBrasil *dnalyra@gmail.com ${ }^{2}$ Centro de Ciências Agrárias, Ambientais e Biológicas, Universidade Federal do Recôncavo da Bahia (UFRB), Rua Rui Barbosa, 710, CEP: 44380-000, Cruz das Almas-Brasil ${ }^{3}$ Departamento de Fitotecnia, Universidade Federal de Viçosa (UFV), Avenida PH Rolfs s/n, CEP: 36570-000, Viçosa-Brasil ${ }^{4}$ Departamento de Ciências Biológicas, Universidade Estadual do Sudoeste da Bahia (UESB), Rua José Moreira Sobrinho, s/n, CEP: 45206-510, Jequié-Brasil
\end{abstract}

\begin{abstract}
RESUMO: O objetivo deste trabalho foi estimar parâmetros genéticos de frutos, sementes e plântulas de Jatropha ribifolia (Pohl) Baill., subsidiando futuros programas de melhoramento e conservação genética. Foram selecionadas 20 matrizes da espécie e os frutos coletados em área de Caatinga, no Município de Jequié - BA / Brasil. Para descrição morfológica foram observadas características de 50 frutos e 50 sementes. Para germinação foi utilizado o delineamento experimental inteiramente casualizado com 20 tratamentos (progênie) e três repetições de 20 sementes. O fruto de J. ribifolia é seco, cápsula loculicida e septicida, endocarpo lenhoso e deiscência explosiva (autocórica). A semente é oval, endospérmica, de testa lisa, com diferentes colorações e carúncula presa na parte ventral. O hilo é visível e a rafe bem marcada longitudinalmente. Agerminação é hipógea-criptocotiledonar. O tempo médio para germinação foi de 10 a 40 dias. As matrizes de J. ribifolia estudadas apresentaram variabilidade genética significativa para a maioria dos caracteres estudados.
\end{abstract}

Palavras-chave: plantas medicinais, semi-árido, germoplasma, traços

ABSTRACT: Genetic parameters of fruits, seeds and seedlings of Jatropha ribifolia (Pohl) Baill. (Euphorbiaceae). The aim of this study was to estimate genetic parameters of fruits, seeds and seedlings of Jatropha ribifolia (Pohl) Baill, subsidizing future breeding and genetic conservation programs. Twenty matrices of the species and the fruits collected in the Caatinga area in the city of Jequie - BA / Brazil were selected. For morphological description, the features of 50 fruits and 50 seeds were observed. For germination, completely randomized design was used with 20 treatments (progeny) and three replicates of 20 seeds. J. ribifolia fruit is dry and has loculicidal and septicidal capsule, woody endocarp and explosive dehiscence (autochory). The seed is oval, endospermic and has smooth testa and different colors, with caruncle attached to the ventral part. The hilum is visible and the raphe is longitudinally marked. Germination is hypogealcryptocotylar. The average time for germination was from 10 to 40 days. The matrices of $J$. ribifolia showed significant genetic variability for most of the studied traits.

Key words: medicinal plants, semi-arid, germplasm, traits

\section{INTRODUÇÃO}

$\mathrm{Na}$ Caatinga, especialmente, a do SemiÁrido Nordestino, ações antrópicas vêm continuamente afetando a diversidade das espécies medicinais e, dependendo do grau de exploração, causa a perda irreversível da diversidade biológica, pela erosão genética, acentuada por meio da depressão endogâmica (Cançado \& Borém, 2001; Silva et al., 2003).
O gênero Jatropha L. (Euphorbiaceae) é, amplamente, distribuído no bioma supracitado, sendo constituído por espécies de grande importância econômica, principalmente, pelo uso medicinal, dentre outros (Sátiro \& Roque, 2008; Rao et al., 2008).

A J. ribifolia, popularmente conhecida como pinhão de purga, arbusto de, em média, 2 metros de altura que apresenta como característica principal a

Recebido para publicação em 01/12/2009

Aceito para publicação em 18/07/2012

Rev. Bras. Pl. Med., Botucatu, v.14, n.4, p.579-585, 2012. 
lâmina foliar tri-lobada e flores amarelas (Leal \& Agra, 2005). É largamente empregada na medicina popular no Nordeste do Brasil, possuindo indicações terapêuticas como antiinflamatória (Agra et al., 2008). O látex é empregado como antiofídico e as sementes são comercializas para extração dos óleos fixos (Agra et al., 2007).

Conforme Scheffer et al. (1999) e Vieira (2002), para a conservação e utilização dos recursos genéticos de plantas medicinais são necessários estudos básicos sobre a biologia reprodutiva, como por exemplo, a germinação. Por outro lado, Souza (2009) e Nunes et al. (2009) relatam a necessidade de estudos morfológicos dos frutos, sementes e plântulas, pois auxiliam na regeneração natural, conservação e domesticação destas espécies.

A domesticação via estimação dos parâmetros genéticos das plantas medicinais, é de suma importância, pois estes auxiliam na obtenção de princípios ativos como componentes essenciais para as indústrias farmacêuticas (Martins et al., 1994; Lopes et al., 2008).

As estimativas de parâmetros genéticos, tais quais a herdabilidade, repetibilidade e correlações genéticas são importantes no conhecimento da estrutura genética e na inferência da variabilidade genética da população, além de proporcionar subsídios para predizer os ganhos genéticos e o possível sucesso no programa de melhoramento e conservação (Cruz \& Carvalho, 2003; Rego et al., 2005).

O objetivo deste trabalho foi estimar parâmetros genéticos de frutos, sementes e plântulas de Jatropha ribifolia (Pohl) Baill., subsidiando futuros programas de melhoramento e conservação genética.

\section{MATERIAL E MÉTODO}

\section{Material Vegetal}

Foram selecionadas e marcadas (placa de alumínio) 20 matrizes de Jatropha ribifolia (Pohl) Baill., em duas localidades, seis delas em área urbana (8465'59.8'S 038³8'82"W, $181 \mathrm{~m}$ de altitude), e as restantes na Fazenda Velha/Curral Novo (84⒍'32.6"'S 037 64'36"W, 194m de altitude), todas localizadas na Caatinga, Município de Jequié-BA, Brasil.

As matrizes foram selecionadas com base na boa capacidade de produção de frutos, conforme as recomendações de Mori (2003) e, visando diminuir a possibilidade de seleção de indivíduos aparentados, como indicado por Shimizu et al. (1982), foi adotada distância mínima entre as matrizes de $100 \mathrm{~m}$.

Para a coleta de sementes, foram colhidos por matriz, frutos em estágio de maturação, sendo colocados para secar em local fechado e com incidência de sol. As sementes foram aleatoriamente escolhidas e coletadas, posteriormente, armazenadas em sacos de papel, no Laboratório de Genética Experimental (LABGENEX) do Departamento de Ciências Biológicas (DCB) da Universidade Estadual do Sudoeste da Bahia (UESB), Campus de JequiéBA. Exsicatas do material estudado estão depositadas no Herbário (HUESB) da mesma instituição sob no 4660, na qual, foi revisada por especialista.

\section{Caracterização dos frutos e sementes}

Foram observadas características externas de 50 frutos, sendo considerados os aspectos de classificação quanto ao tipo, coloração, dimensões (comprimento, largura e espessura), textura e consistência do pericarpo, deiscência e número de sementes.

Características externas e internas foram observadas em 50 sementes. As externas foram cor, dimensões (comprimento, largura e espessura), textura e consistência dos tegumentos, forma, bordo, presença de carúncula e rafe.

As estruturas internas consideradas foram embrião (cotilédones, eixo hipocótilo-radícula) e presença de endosperma. Para permitir o estudo da morfologia interna, as sementes foram imersas em água destilada por 24 horas e fervidas por 10 minutos para amolecimento dos tegumentos, sendo, em seguida seccionadas com auxílio de bisturi e examinadas com lupa (aumento de 6x).

Para análise dos parâmetros genéticos foram realizadas mensurações em 30 frutos e 30 sementes por matriz para comprimento, largura, espessura e peso. Para aferir as medidas foi utilizado paquímetro digital com precisão de $0,01 \mathrm{~mm}$ e o peso determinado em balança eletrônica com precisão de $0,01 \mathrm{~g}$.

Em cada uma das variáveis estudadas, os dados obtidos foram submetidos à análise de variância, estimando o coeficiente de repetibilidade (r) e o coeficiente de determinação $\left(R^{2}\right)$, e as médias foram comparadas pelo teste de Scott-Knott, a 5\% de probabilidade. O modelo estatístico adotado foi com um fator de variação (Cruz et al., 2004).

\section{Germinação}

O experimento foi realizado na Casa de Vegetação da Universidade Estadual do Sudoeste da Bahia - UESB, Campus de Jequié - BA, no período de 25 de maio a 25 de julho de 2009 , totalizando 60 dias.

Foi utilizado o delineamento experimental inteiramente casualizado, com 20 tratamentos (progênie) e três repetições de 20 sementes, totalizando 60 parcelas e 1.200 sementes em todo o experimento. As parcelas foram dispostas em bandejas de isopor contendo como substrato solo, areia e húmus, na proporção de, respectivamente, 3:2:1. 
A germinação foi caracterizada quanto ao tipo e as avaliações dos testes de germinação foram realizadas por meio de contagens diárias, computando-se o número de sementes que apresentavam início de emergência do hipocótilo. Com isto, foi determinado o Índice de Velocidade de Emergência (IVE), que foi calculado conforme a fórmula de Maguire (1962).

O IVE e os dados de germinação foram transformados em arco seno $\sqrt{x(\%) / 100}$, e submetidos à análise de variância, estimando a variância genética entre progênies e a variância fenotípica. Com base nestas estimativas, foram calculados o coeficiente de variação genética $(C V g)$ e o coeficiente de determinação genotípico $\left(b_{i}\right)$, equivalente ao coeficiente de herdabilidade no sentido amplo.

As médias entre progênies foram avaliadas pelo teste de Scott-Knott a 5\% de probabilidade.

\section{Avaliação de plântulas}

No teste de germinação, foi considerada como germinada as sementes que originaram plântulas jovens (raiz, hipocótilo, epicótilo e eofilos). Os elementos vegetativos descritos e ilustrados foram raiz (axial e secundária), coleto, hipocótilo, folha cotiledonar e eofilo.

Foram avaliados em todas as progênies $O$ comprimento $(\mathrm{mm})$ da parte aérea (CPA), comprimento $(\mathrm{mm})$ da raiz $(\mathrm{CR})$, diâmetro $(\mathrm{mm})$ do colo (DC), número de folhas (NF) e número de gemas axilares protegidas por catáfilos (GAP).

O delineamento experimental utilizado foi o inteiramente casualizado, com 20 tratamentos (progênie) e 5 repetições, totalizando 100 parcelas e 100 plântulas em todo o experimento.

Os dados para os caracteres, número de folhas e número de gemas protegidas por catáfilos foram transformados em $\sqrt{x+0,5}$ e submetidos à análise de variância, estimando a variância genética entre progênies e a variância fenotípica, coeficiente de variação genética e o coeficiente de determinação genotípico. As médias entre progênies foram comparadas pelo teste de Scott-Knott a 5\% de probabilidade.

Todas as análises estatísticas utilizadas nos experimentos foram realizadas utilizando o programa computacional GENES (Cruz, 2006).

\section{RESULTADO E DISCUSSÃO}

Aspectos morfológicos de frutos e sementes

O fruto de J. ribifolia é seco, cápsula loculicida e septicida, endocarpo lenhoso e deiscência fortemente explosiva (autocórica) (Figuras $1 \mathrm{Ae} \mathrm{C}$ ). A coloração natural é verde e de superfície lisa; na fase madura é marrom, e o pericarpo apresenta duas zonas distintas, o exocarpo, película mais fina, e o endocarpo, mais grosso. Próximo à deiscência, o exocarpo desprende-se do fruto, dando-Ihe aspecto mais áspero.

Os frutos têm, em média, 10,12 $\pm 1,48 \mathrm{~mm}$ de comprimento, $9,28 \pm 1,35 \mathrm{~mm}$ de largura, 9,03 \pm $1,43 \mathrm{~mm}$ de espessura e $0,55 \pm 0,12 \mathrm{~g}$ de peso, geralmente, apresentando três sementes, 1 por lóculo (Figura 1B).

A semente é oval, de dorso convexo, endospérmica, de testa lisa e de diferentes colorações, apresentando grande variação e carúncula bem desenvolvida incisa na parte ventral. O hilo é visível na base e a rafe é bem marcada longitudinalmente na semente (Figura 2A). O embrião é reto, com dois cotilédones planos, arredondados, com nervação marcada e eixo hipocótilo-radícula cilíndrico e reto (Figura 2B).

As sementes têm, em média, 7,46 $\pm 0,71$ $\mathrm{mm}$ de comprimento, $3,82 \pm 0,47 \mathrm{~mm}$ de largura, 2,75 $\pm 0,32 \mathrm{~mm}$ de espessura e $0,045 \pm 0,01 \mathrm{~g}$ de peso.
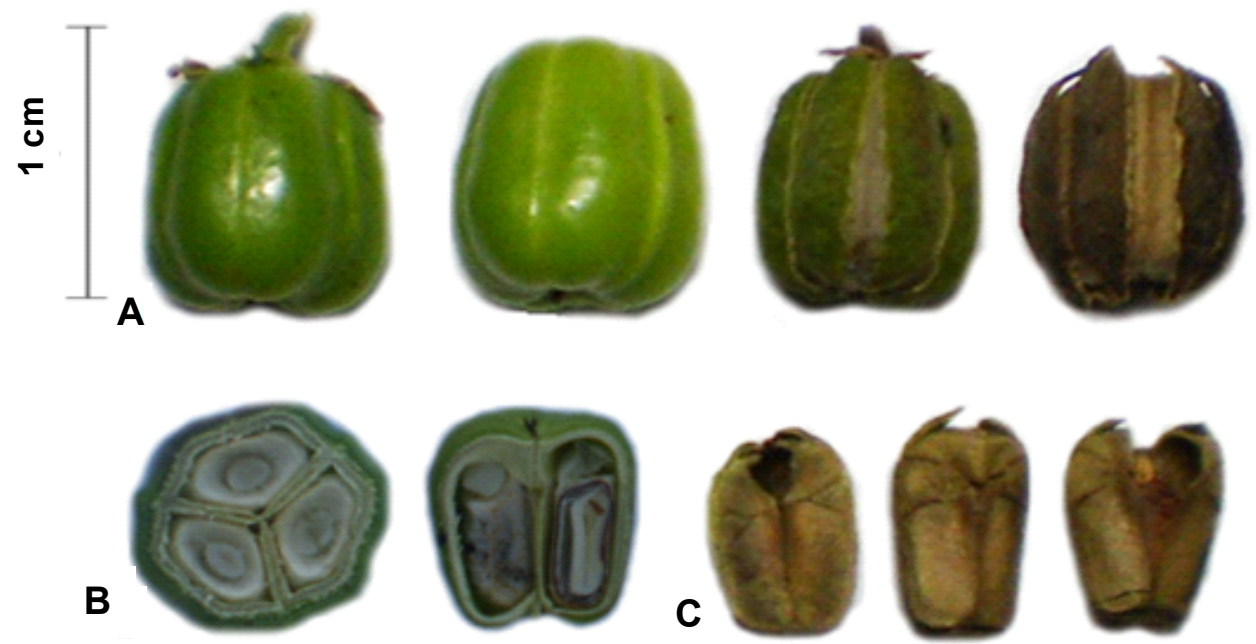

FIGURA 1. (A) Estágio do desenvolvimento, (B) corte transversal e longitudinal e (C) mericarpo de J. ribifolia. 

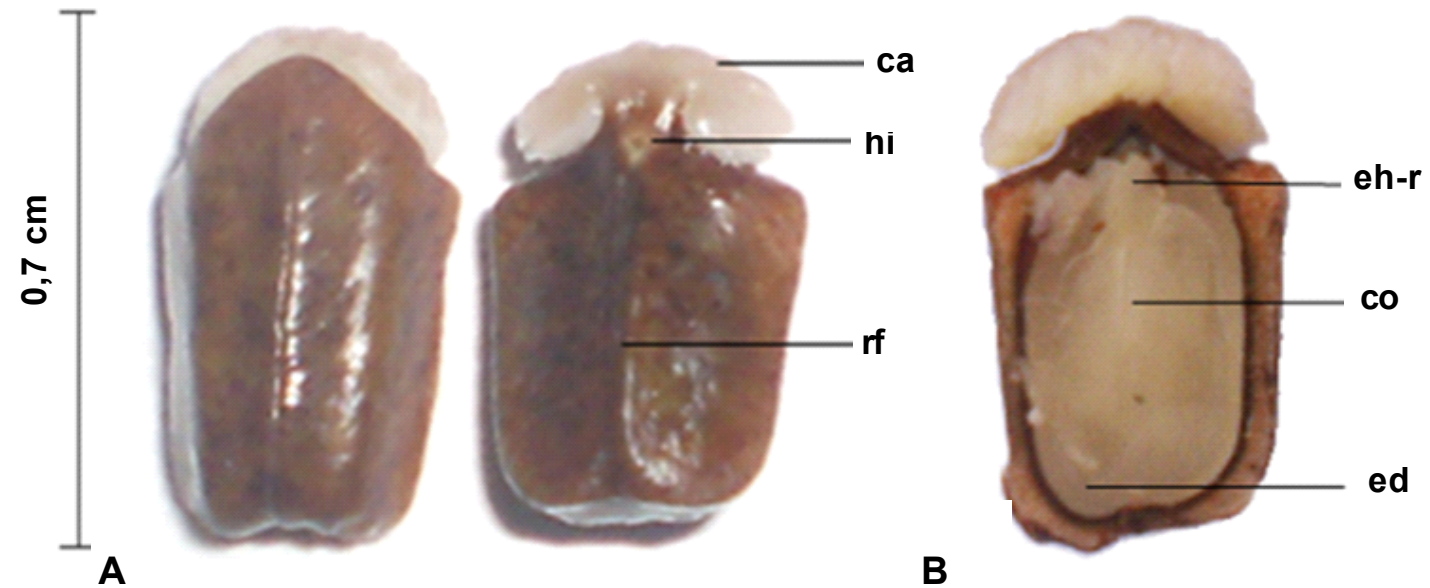

FIGURA 2. (A) Parte externa e (B) interna da semente de J. ribifolia. (ca = carúncula, hi $=$ hilo, $r f=$ rafe, $c o=$ cotilédones, ed = endosperma, eh-r $=$ eixo hipocótilo radícula).

\section{Germinação e morfologia da plântula}

Os estágios sequenciais da emergência e desenvolvimento da plântula estão ilustrados na Figura 3. O início da emergência mostra uma raiz principal branca, normalmente, com cinco raízes formadas, sendo uma axial e quatro secundárias. O tempo médio para germinação, considerada como emissão do hipocótilo, foi de 10 a 40 dias.

A formação do sistema radicular ocorre com desenvolvimento do hipocótilo, de coloração brancoesverdeada (Figura 3A). Os cotilédones são envolvidos inteiramente pelo endosperma, que é, relativamente, espesso e de coloração branca (Figura 3B). Em torno de dez dias após a emissão da radícula, as folhas cotiledonares estão completamente expandidas (Figura 3C).

O tipo de germinação observado é hipógeacriptocotiledonar (Figura 3A), pois foi verificado que os cotilédones apresentavam-se mais ou menos no nível do solo, encobertos pelo tegumento. Añez et al. (2005) e Nunes et al. (2009) ao trabalharem com J. elliptica e J. curcas, respectivamente, verificaram uma germinação epígea e fanerocotiledonar para ambas, enfatizando variações quanto ao tipo de germinação no gênero.

As plântulas jovens (Figura 3D) foram caracterizadas por apresentar raiz axial e secundárias marrons, finas, cônicas, pilosas e com pêlos radiculares; hipocótilo avermelhado, cilíndrico, liso e glabro, apresentando espessamento na base, próximo à raiz. As folhas são pecioladas, ovadas, verdes, margens lisas, ápice e base obtusa, peninérveas, sendo a nervura principal bastante evidente, impressa nas duas faces sendo as nervuras secundárias também bem visíveis.

No 22 dia, o epicótilo tornou-se ereto, sendo observado, nesta fase, o surgimento da primeira gema
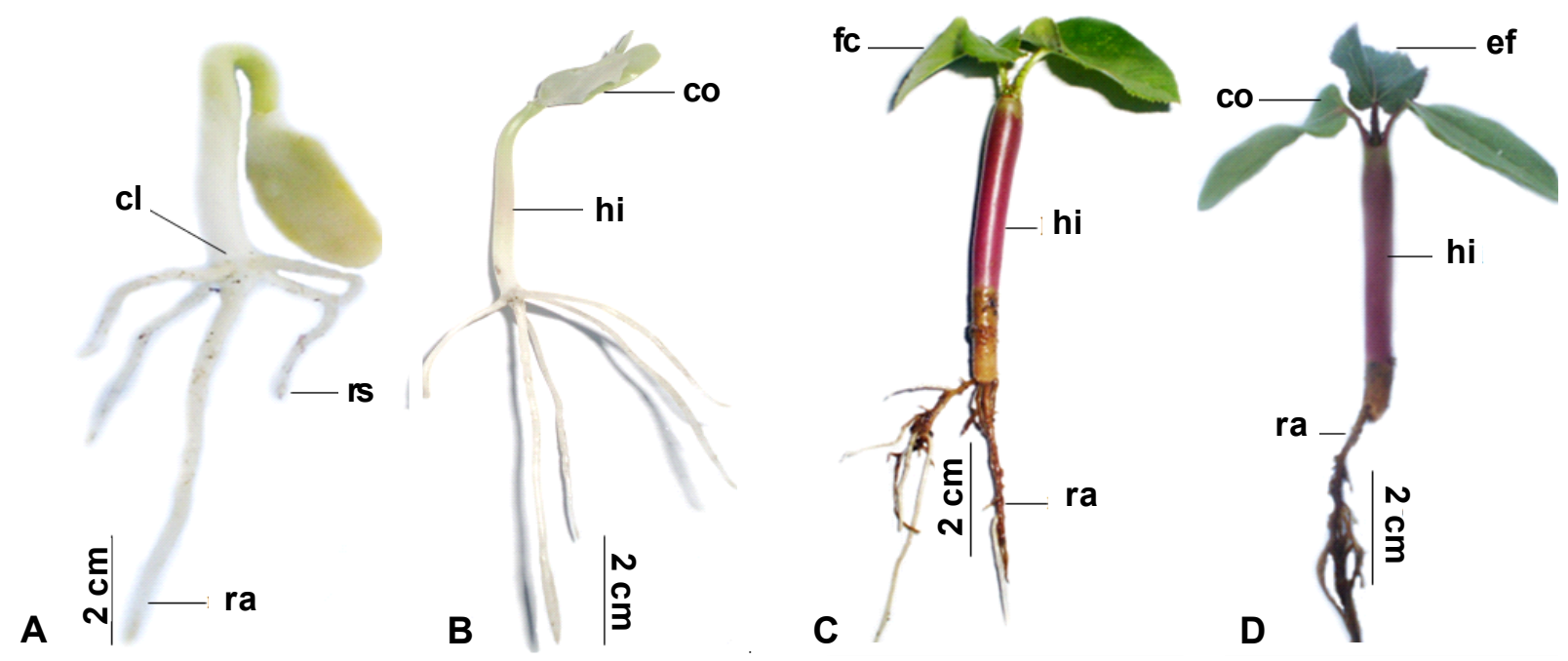

FIGURA 3. Estádios de germinação de J. ribifolia. (A) germinação hipógea-criptocotiledonar (B) cotilédones recobertos por tegumento de cor branca; $(\mathbf{C})$ aparecimento do primeiro par de protófilos; (D) plântulas jovens. (hi = hilo, $\mathrm{ra}=$ raiz axial, $\mathrm{rs}=$ raiz secundária, $\mathrm{cl}=\mathrm{colo}, \mathrm{co}=$ cotilédones, $\mathrm{fc}=$ folha cotiledonar, ef $=$ eofilo). 
TABELA 1. Quadrado médio da progênie e resíduo com as médias gerais, coeficiente de variação (CV\%), estimativas do coeficiente de variação genética $(\mathrm{CVg} \%)$ e estimativas de herdabilidade ( $\left.\mathrm{h}^{2} \mathrm{amplo}\right)$, para porcentagem de germinação (GER), índice de velocidade de emergência (IVE), comprimento da parte aérea (CPA), comprimento da raiz (CR), diâmetro do colo (DC), número de folhas (NF) e número de gemas axilares protegidas por catáfilos (GPC). Jequié-BA, Brasil, 2009.

\begin{tabular}{cccccccc}
\hline FV & GER & IVE & CPA $(\mathbf{c m})$ & CR $(\mathbf{c m})$ & DC $(\mathbf{m m})$ & NF & GPC \\
\hline Progênie & $0.025^{*}$ & $0.049^{\text {ns }}$ & $58.07^{* *}$ & $116.1^{* *}$ & $1.23^{* *}$ & $0.04^{\text {ns }}$ & $0.11^{\text {ns }}$ \\
Resíduo & 0.010 & 0.047 & 14.85 & 20.43 & 0.31 & 0.02 & 0.07 \\
Médias & 0.30 & 0.25 & 25.82 & 28.91 & 2.38 & 1.70 & 0.92 \\
CV $(\%)$ & 34.30 & 85.90 & 14.92 & 15.63 & 23.58 & 9.20 & 29.28 \\
CVg (\%) & 22.49 & 9.35 & 11.38 & 15.13 & 18.02 & 3.27 & 9.96 \\
$H^{2}$ & 56.32 & 3.43 & 74.41 & 82.40 & 74.49 & 38.7 & 36.64 \\
\hline
\end{tabular}

${ }^{*}$ Significativo a $5 \%$ de probabilidade pelo teste $\mathrm{F}{ }^{* *}$ Significativo a $1 \%$ de probabilidade pelo teste $\mathrm{F}$

auxiliar protegida por catáfilos, e o segundo par de eofilos trilobados, peciolados, verdes, peltados, denteados e peninérveos com nervuras secundárias ao longo da principal.

A duração da germinação e desenvolvimento da plântula jovem varia de 10 a 35 dias. De acordo com Oliveira \& Pereira (1987), Añez et al. (2005) e Nunes et al. (2009), ao trabalharem com J. mollissima, $J$. elliptica e $J$. curcas, respectivamente, verificaram que o tempo de desenvolvimento da plântula jovem varia de 7 a 16 dias, 20 a 32 e 15 a 30 dias.

Os maiores percentuais de germinação foram verificados na matriz $4(63,20 \%), 10(55 \%)$ e $3(48,7 \%)$, e os menores na $6(10 \%)$, nas 7, 19 e $20(11,7 \%)$. Resultados similares foram evidenciados por Oliveira \& Pereira (1987), constatando percentual de germinação para J.mollissima de $20-30 \%$, enquanto Ginwal et al. (2005) de 57-78\% para J.curcas.

Os maiores índices de velocidade de emergência (IVE) médio foram verificados na matriz 1 $(0,60),(0,40)$ e $14(0,46)$, demonstrando que a reposta germinativa nestas matrizes é mais rápida em relação às demais. Segundo Ginwal \& Gera (2000), sementes que germinam mais rápidas e vigorosas em condições favoráveis são susceptíveis a produzirem mudas vigorosas em condições de campo.

\section{Parâmetros genéticos}

Os maiores coeficientes de variação foram obtidos para os caracteres índice de velocidade de emergência e porcentagem de geminação. Para os demais parâmetros, os valores obtidos oscilaram de baixos a médios (Tabelas 1 e 2). Considerando-se a origem do material em estudo, estes valores indicam boa precisão experimental, que se traduz em confiabilidade nos resultados apresentados.

Segundo Cruz (2005), o conhecimento da herdabilidade em parâmetros de interesse é fundamental para que a seleção seja aplicada com sucesso, de forma que o valor fenotípico de um caráter possa servir como guia para o valor genético.

As estimativas de herdabilidade no sentido amplo $\left(\mathrm{H}^{2}\right)$ foram elevadas, para o comprimento da parte aérea, comprimento da raiz e diâmetro do colo, que aliadas à variabilidade genética entre as matrizes, evidenciam que a seleção com base nestes caracteres é promissora (Tabela 1).

Estimativas do coeficiente de variação genética $(\mathrm{CVg})$ apresentadas na Tabela 1 revelaram que, dentre as características avaliadas, as mais variáveis geneticamente na população são, respectivamente, porcentagem de germinação, diâmetro do colo e comprimento da raiz, enquanto que o número de folhas, apresentou menor variação.

De acordo com Ferrão et al. (2008), as estimativas do $\mathrm{CVg}$ é de suma importância para a estrutura genética de populações, por expressar a quantidade de variação existente entre os materiais genéticos. Demonstrando, então, que a presença de variabilidade genética pode ser confirmada e quantificada pelo mesmo.

$\mathrm{Na}$ Tabela 2, encontram-se os resultados referentes às estimativas do coeficiente de repetibilidade, determinação e o número de medições necessárias para se ter diferentes valores de predição do valor real. Percebe-se que, para os caracteres CS, ES, LS, CF, LF e EF são necessárias de 2.57 a 15.73 medições, para obter predições com confiabilidade em torno de $95 \%$.

O coeficiente de determinação $\left(R^{2}\right)$ foi acima de $80 \%$ para todos os caracteres. Os índices de repetibilidade da largura de sementes, comprimento, largura e espessura de frutos, foram altos, o que pode ser considerado um ótimo valor (Tabela 2 ).

De acordo com o trabalho realizado por Silva et al. (2009), pode-se dizer que estes valores demonstram uma alta regularidade na repetição do caráter de uma avaliação para outra, sendo possível a predição do real valor dos indivíduos com poucas 
TABELA 2. Quadrado médio da progênie e resíduo com as médias gerais, estimativas do coeficiente de repetibilidade ( $r$ ) e número de medições em diferentes coeficientes de determinação $\left(R^{2}\right)$, para comprimento $(C S, m m)$, espessura (ES, mm), largura (LS, mm) e peso de sementes (PS), comprimento (CF), largura (LF), espessura (EF), peso (PF) e número de sementes (NS), de frutos. Jequié-BA, Brasil, 2009.

\begin{tabular}{ccccccccc}
\hline FV & CS $(\mathbf{m m})$ & ES $(\mathbf{m m})$ & LS $(\mathbf{m m})$ & PS $(\mathbf{g})$ & CF $(\mathbf{m m})$ & LF $(\mathbf{m m})$ & EF $(\mathbf{m m})$ & PF $(\mathbf{g})$ \\
\hline Matriz & $0.51^{* *}$ & $1.80^{* *}$ & $5.29^{* *}$ & $0.00081^{* *}$ & $54.75^{* *}$ & $46.03^{* *}$ & $56.76^{* *}$ & $0.1975^{* *}$ \\
Resíduo & 0.18 & 0.04 & 0.05 & 0.000093 & 0.48 & 0.377 & 0.25 & 0.0093 \\
\hline Médias & 7.46 & 2.74 & 3.81 & 0.040 & 10.11 & 9.27 & 9.03 & 0.55 \\
CV $(\%)$ & 23.5 & 8.01 & 6.17 & 23.77 & 6.90 & 6.62 & 5.59 & 17.49 \\
r & 0.65 & 0.54 & 0.75 & 0.20 & 0.78 & 0.80 & 0.88 & 0.40 \\
$\mathrm{R}^{2}(0,90)$ & 4.76 & 7.45 & 2.87 & 34.63 & 2.42 & 2.23 & 1.21 & 13.48 \\
$\mathrm{R}^{2}(0,95)$ & 10.06 & 15.73 & 6.06 & 73.11 & 5.11 & 4.71 & 2.57 & 28.47 \\
$\mathrm{R}^{2}(0,99)$ & 52.43 & 82.00 & 31.59 & 380.94 & 26.67 & 24.58 & 13.40 & 148.35 \\
\hline
\end{tabular}

${ }^{* *}$ Significativo a $1 \%$ de probabilidade pelo teste $\mathrm{F}$

avaliações e um nível de precisão significativo.

As médias mostraram diferenças significativas entre si na maioria dos parâmetros avaliados (Tabela 3). Um maior número de diferenças significativas foi observado para o caráter comprimento (CF), largura
(LF) e espessura (EF) do fruto.

Kaushik et al. (2007), trabalhando com parâmetros genéticos em sementes de J. curcas, verificaram diferenças significativas $(p<0,05)$ no tamanho e peso das sementes entre 24 acessos.

TABELA 3. Médias dos caracteres avaliados nas 20 matrizes para porcentagem de germinação (GER), comprimento (CS, mm), espessura (ES, mm), largura (LS, mm) e peso de sementes (PS), comprimento (CF), largura (LF), espessura (EF) e peso (PF) de frutos, comprimento da parte aérea (CPA), comprimento da raiz (CR) e diâmetro do colo (DC).

\begin{tabular}{|c|c|c|c|c|c|c|c|c|c|c|c|c|}
\hline Matriz & $\begin{array}{l}\text { GER } \\
\text { (\%) }\end{array}$ & $\begin{array}{c}\text { CS } \\
(\mathrm{mm})\end{array}$ & $\begin{array}{c}E S \\
(\mathrm{~mm})\end{array}$ & $\begin{array}{c}\text { LS } \\
(\mathrm{mm})\end{array}$ & $\begin{array}{l}\text { PS } \\
\text { (g) }\end{array}$ & $\begin{array}{c}\text { CF } \\
(\mathrm{mm})\end{array}$ & $\begin{array}{c}\text { LF } \\
(\mathrm{mm})\end{array}$ & $\begin{array}{c}\text { 帛 } \\
(\mathrm{mm})\end{array}$ & $\begin{array}{l}\text { PF } \\
\text { (g) }\end{array}$ & $\begin{array}{c}\text { CPA } \\
(\mathrm{mm})\end{array}$ & $\begin{array}{c}\text { CR } \\
(\mathrm{mm})\end{array}$ & $\begin{array}{c}\mathrm{DC} \\
(\mathrm{mm})\end{array}$ \\
\hline 1 & $11.63 a^{*}$ & $7.624 b$ & $2.854 \mathrm{~b}$ & $4.036 \mathrm{~b}$ & $0.040 \mathrm{c}$ & $10.450 \mathrm{c}$ & $9.735 \mathrm{c}$ & $9.225 \mathrm{c}$ & $0.525 \mathrm{c}$ & $28.060 \mathrm{a}$ & $31.298 a$ & $3.388 \mathrm{a}$ \\
\hline 2 & $7.20 \mathrm{~b}$ & $7.710 a$ & $2.713 b$ & $3.965 c$ & $0.043 b$ & $10.856 b$ & $9.725 c$ & $9.317 \mathrm{c}$ & $0.561 \mathrm{c}$ & $28.010 \mathrm{a}$ & $23.956 b$ & $1.784 \mathrm{~b}$ \\
\hline 3 & $16.10 \mathrm{a}$ & $7.888 a$ & $2.764 b$ & $3.935 c$ & $0.040 \mathrm{c}$ & $10.679 b$ & $9.527 \mathrm{c}$ & $9.199 \mathrm{c}$ & $0.648 a$ & $19.862 b$ & $23.948 b$ & $1.866 b$ \\
\hline 4 & $21.06 a$ & $7.962 \mathrm{a}$ & $2.798 b$ & $3.968 c$ & $0.043 b$ & $10.406 \mathrm{c}$ & $9.035 d$ & $8.969 d$ & $0.528 \mathrm{c}$ & $22.118 b$ & $35.842 \mathrm{a}$ & $2.960 \mathrm{a}$ \\
\hline 5 & $11.63 a$ & $7.778 a$ & $2.826 b$ & $3.922 \mathrm{c}$ & $0.047 \mathrm{a}$ & $10.183 d$ & $9.539 c$ & $9.197 \mathrm{c}$ & $0.532 \mathrm{c}$ & $26.038 a$ & $36.312 \mathrm{a}$ & $2.514 b$ \\
\hline 6 & $14.96 \mathrm{a}$ & $7.523 b$ & $2.763 b$ & $3.892 \mathrm{c}$ & $0.040 \mathrm{c}$ & $10.409 c$ & $9.634 \mathrm{c}$ & $9.056 \mathrm{~d}$ & $0.524 \mathrm{c}$ & $28.360 \mathrm{a}$ & $38.812 a$ & $2.438 b$ \\
\hline 7 & $9.40 \mathrm{a}$ & $7.567 b$ & $2.772 b$ & $3.867 \mathrm{c}$ & $0.035 d$ & $8.336 \mathrm{e}$ & $7.662 \mathrm{e}$ & $7.163 \mathrm{e}$ & $0.453 d$ & $25.016 a$ & $25.708 b$ & $2.290 \mathrm{~b}$ \\
\hline 8 & $13.86 \mathrm{a}$ & $7.471 \mathrm{c}$ & $2.827 b$ & $3.930 \mathrm{c}$ & $0.032 \mathrm{~d}$ & $7.487 \mathrm{f}$ & $7.778 \mathrm{e}$ & $7.257 \mathrm{e}$ & $0.462 \mathrm{~d}$ & $20.552 b$ & $26.534 b$ & $1.802 b$ \\
\hline 9 & $11.63 a$ & $7.456 \mathrm{c}$ & $2.776 b$ & $3.923 c$ & $0.034 \mathrm{~d}$ & $6.110 \mathrm{~g}$ & $5.054 \mathrm{f}$ & $4.722 \mathrm{f}$ & $0.551 \mathrm{c}$ & $22.416 b$ & $25.248 b$ & $2.018 b$ \\
\hline 10 & $18.26 \mathrm{a}$ & $7.624 b$ & $2.722 b$ & $3.808 \mathrm{c}$ & $0.036 \mathrm{~d}$ & $9.744 d$ & $9.063 d$ & $8.655 d$ & $0.422 d$ & $30.092 a$ & $33.822 \mathrm{a}$ & $2.890 \mathrm{a}$ \\
\hline 11 & $8.30 \mathrm{~b}$ & $7.235 \mathrm{c}$ & $2.711 b$ & $3.933 c$ & $0.045 b$ & $9.964 \mathrm{~d}$ & $9.224 d$ & $8.840 d$ & $0.460 \mathrm{~d}$ & $29.038 a$ & $32.950 \mathrm{a}$ & $2.644 \mathrm{a}$ \\
\hline 12 & $3.86 b$ & $7.814 a$ & $2.932 \mathrm{a}$ & $4.209 a$ & $0.042 b$ & $10.028 d$ & $9.364 d$ & $8.947 d$ & $0.452 d$ & $26.982 a$ & $23.228 b$ & $2.950 \mathrm{a}$ \\
\hline 13 & $3.30 \mathrm{~b}$ & $7.914 \mathrm{a}$ & $2.924 \mathrm{a}$ & $4.131 \mathrm{a}$ & $0.039 \mathrm{c}$ & $9.984 \mathrm{~d}$ & $9.361 \mathrm{~d}$ & $8.857 d$ & $0.596 b$ & $26.916 a$ & $28.060 \mathrm{~b}$ & $3.200 \mathrm{a}$ \\
\hline 14 & $6.63 b$ & $7.595 b$ & $2.847 b$ & $3.976 \mathrm{c}$ & $0.046 a$ & $10.496 c$ & $9.705 \mathrm{c}$ & $9.452 \mathrm{c}$ & $0.545 \mathrm{c}$ & $20.890 \mathrm{~b}$ & $25.062 b$ & $2.252 b$ \\
\hline 15 & $7.20 \mathrm{~b}$ & $7.801 \mathrm{a}$ & $2.842 b$ & $3.823 c$ & $0.040 \mathrm{c}$ & $11.003 b$ & $9.846 \mathrm{c}$ & $10.529 a$ & $0.669 a$ & $25.998 a$ & $27.474 b$ & $1.614 \mathrm{~b}$ \\
\hline 16 & $12.16 \mathrm{a}$ & $7.581 \mathrm{~b}$ & $2.819 b$ & $3.909 c$ & $0.036 \mathrm{~d}$ & $11.285 a$ & $10.093 b$ & $10.700 \mathrm{a}$ & $0.688 a$ & $29.786 a$ & $30.564 a$ & $2.464 \mathrm{~b}$ \\
\hline 17 & $8.30 \mathrm{~b}$ & $5.850 \mathrm{~d}$ & $1.850 \mathrm{~d}$ & $2.413 e$ & $0.033 d$ & $11.152 \mathrm{a}$ & $9.889 \mathrm{c}$ & $10.456 a$ & $0.695 a$ & $26.204 \mathrm{a}$ & $32.744 \mathrm{a}$ & $2.028 b$ \\
\hline 18 & $12.20 \mathrm{a}$ & $5.783 d$ & $2.367 c$ & $2.868 d$ & $0.033 d$ & $11.379 a$ & $10.553 \mathrm{a}$ & $10.078 b$ & $0.561 \mathrm{c}$ & $30.570 a$ & $28.190 \mathrm{~b}$ & $2.042 b$ \\
\hline 19 & $3.86 \mathrm{~b}$ & $7.687 \mathrm{a}$ & $2.819 b$ & $3.951 \mathrm{c}$ & $0.050 \mathrm{a}$ & $11.240 \mathrm{a}$ & $10.431 \mathrm{a}$ & $10.088 b$ & $0.619 b$ & $21.718 b$ & $22.684 \mathrm{~b}$ & $2.120 \mathrm{~b}$ \\
\hline 20 & $3.83 b$ & $7.421 \mathrm{c}$ & $3.009 a$ & $3.921 \mathrm{c}$ & $0.047 a$ & $11.106 a$ & $10.359 a$ & 9.977 b & $0.580 \mathrm{~b}$ & $27.928 a$ & $25.850 \mathrm{~b}$ & $2.422 b$ \\
\hline
\end{tabular}

*Médias seguidas por letras iguais na mesma coluna pertencem ao mesmo grupo pelo teste de Scott-Knott, a $5 \%$ de probabilidade. 
Ginwal et al. (2005), estudando a mesma espécie, relataram grande variabilidade quanto à variação de sementes com base na morfologia, germinação e crescimento das plântulas.

As matrizes 1, 3, 4, 5, 6, 7, 8, 9, 10, 16 e 18 apresentaram as maiores médias para porcentagem de germinação (GER\%). Em relação ao comprimento da semente (CS), sobressaíram-se as matrizes 2, 3 , $4,5,12,13,15$ e 19. Por sua vez, as matrizes 16, $17,18,19$ e 20, tiveram as maiores médias para o comprimento do fruto (CF).

A matriz 16 apresentou as maiores médias para $50 \%$ dos caracteres estudados sendo, portanto, indicada para fornecer sementes destinadas a programas de conservação e/ou melhoramento genético da espécie.

Assim, pode-se concluir que as matrizes de J. ribifolia estudadas apresentaram variabilidade genética significativa para a maioria dos parâmetros, ao nível de $5 \%$ de probabilidade, indicando a possibilidade de seleção de plantas superiores, contribuindo para a conservação.

\section{REFERÊNCIA}

AGRA, M.F. et al. Synopsis of the plants known as medicinal and poisonous in Northeast of Brazil. Revista Brasileira de Farmacognosia, v.17, p.114-40, 2007.

AGRA, M.F. et al. Survey of medicinal plants used in the region Northeast of Brazil. Revista Brasileira de Farmacognosia, v.18, p.472-508, 2008.

AÑEZ, L.M. et al. Caracterização morfológica dos frutos, das sementes e do desenvolvimento das plântulas de Jatropha elliptica Müll. Arg. (Euphorbiaceae). Revista Brasileira de Botânica, v.28, p.563-8, 2005.

CANÇADO, G.M.A.; BORÉM, A. Biodiversidade, agropecuária e sustentabilidade. Informe Agropecuário, v.22, n.213, p.39-45, 2001.

CRUZ, E.D.; CARVALHO, J.E.U. Biometria de frutos e germinação de sementes de Couratari stellata A.C. Smith (Lecythidaceae). Acta Amazonica, v.33, n.3, p.381-8, 2003.

CRUZ, C.D.; REGAZZI, A.J.; CARNEIRO, P.C.S. Modelos biométricos aplicados ao melhoramento genético. 3.ed. Viçosa: UFV, 2004. 480p.

CRUZ, C.D. Princípios de genética quantitativa. Viçosa: UFV, 2005. 394p.

CRUZ, C.D. Programa genes: estatística experimental e matrizes. Viçosa: UFV, 2006. 285p.

FERRÃO, R.G. et al. Parâmetros genéticos em café conilon. Pesquisa Agropecuária Brasileira, v.43, p.619, 2008.

GINWAL, H.S.; GERA, M. Genetic variation in seed germination and growth performance of 12 Acacia nilotica provenances in India. Journal of Tropical Forest Science, v.12, n.2, p.286-97, 2000.

GINWAL, H.S. et al. Seed source variation in morphology, germination and seedling growth of Jatropha curcas
Linn., in Central India. Silvae Genetica, v.54, p.76-80, 2005.

KAUSHIK, N. et al. Genetic variability and divergence studies in seed traits and oil content of Jatropha (Jatropha curcas L.) accessions. Biomass Bioenergy, v.31, p.497-502, 2007.

LEAL, C.K.A.; AGRA, M.F. Estudo farmacobotânico comparativo das folhas de Jatropha molissima (Pohl) Baill. e Jatropha ribifolia (Pohl) Baill. (Euphorbiaceae).

Acta Farmaceutica Bonaerense, v.24, p.5-13, 2005.

LOPES, I.L.M.; JARDIM, M.A.G.; MEDEIROS, T.D.S. Germinação e desenvolvimento morfológico de plantas oleaginosas de floresta de várzea. Revista Brasileira de Farmácia, v.89, p.252-4, 2008.

MAGUIRE, J.D. Speed of germination: aid in selection and evaluation for seedling emergence and vigor. Crop Science, v.2, n.2, p.176-7, 1962.

MARTINS, E.R. et al. Plantas medicinais. Viçosa: UFV, 1994. 220p.

MORI, E.S. Genética de populações arbóreas: orientações básicas para seleção e marcação de matrizes. Instituto Florestal - Séries Registros, v.1, n.25, p.35-44, 2003.

NUNES, C.F. et al. Morfologia externa de frutos, sementes e plântulas de pinhão-manso. Pesquisa Agropecuária Brasileira, v.44, n.2, p.207-10, 2009.

OLIVEIRA, E.C.; PEREIRA, T.S. Euphorbiaceae: morfologia da germinação de algumas espécies. Revista Brasileira de Sementes, v.9, p.9-51, 1987.

RAO, G.R. et al. Genetic associations, variability and diversity in seed characters, growth, reproductive phenology and yield in Jatropha curcas (L.) accessions. Trees - Structure and Function, v.22, p.697-709, 2008. REGO, F.L.H. et al. Variabilidade genética e estimativa de herdabilidade para o caráter germinação em matrizes de Albizia lebbeck. Ciência Rural, v.35, n.5, p.1209-12, 2005.

SÁTIRO, L.N.; ROQUE, N. A família Euphorbiaceae nas Caatingas arenosas do médio rio São Francisco, BA, Brasil. Acta Botanica Brasilica, v.22, n.1, p.99-118, 2008. SCHEFFER, M.C.; MING, L.C.; ARAÚJO, A.J. Conservação de recursos genéticos de plantas medicinais. In: QUEIROZ, M.A.; GOEDERT, C.O.; RAMOS, S.R.R. (Eds). Recursos genéticos e melhoramento de plantas para o nordeste Brasileiro. Brasília: Editora da Embrapa - Sede / DF, 1999. 24p.

SILVA, J.M.C. et al. Biodiversidade da Caatinga: áreas e ações prioritárias para a conservação. Brasília: Ministério do Meio Ambiente, 2003. 37p.

SILVA, R.G. et al. Repetibilidade e correlações fenotípicas de caracteres do fruto de bacuri no Estado do Maranhão. Acta Scientiarum. Agronomy, v.31, n.4, p.587-91, 2009.

SHIMIZU, J.Y.; KAGEYAMA, P.Y.; HIGA, A.R. Procedimentos e recomendações para estudos de progênies de essências florestais. Curitiba: EMBRAPA/ URPFCS, 1982. 34p.

SOUZA, L.A. Sementes e plântulas: germinação, estrutura e adaptação. Ponta Grossa: Toda palavra, 2009. 279p.

VIEIRA, R.F. Conservação de recursos genéticos de plantas medicinais e aromáticas brasileiras: um desafio para o futuro. Acta Horticulturae, v.569, p.61-8, 2002. 